\title{
Developing Derrida's Psychoanalytic Graphology: Diametric and Concentric Spatial Movements
}

\section{Paul Downes}

\begin{abstract}
Derrida's work encompasses dynamic spatial dimensions to understanding as a pervasive theme, including the search for a 'new psychoanalytic graphology' in Writing and Difference. This preoccupation with a spatial text for repression also occurs later in Archive Fever. Building on Derrida, this paper seeks to develop key aspects of a new dynamic psychoanalytic graphology through diametric and concentric interactive spatial relation. These spatial movements emerge from a radical reconstruction of a neglected aspect of structural anthropologist LéviStrauss' work on spatial relations prior to myth. This psychoanalytic graphology is argued to silently pervade Freud's own direct accounts of repression. This graphological domain is developed through diametric and concentric spatial movements across common concerns of Derrida and Freud such as inversions, interruption and restoration, regarding traces in the unconscious. A spatial text is uncovered for diverse features of Freudian repression, including ambivalence in obsessional neurosis and psychosis, splitting of the ego and repetition compulsion. This psychoanalytic graphology challenges the construction of a restricted subjectivity based on repressive diametric spatial relations. It goes beyond Freud's logocentric repression, resonant with Derrida's more radical call for a wider spatio-temporal understanding of structures of differential relation, prior to causality and myth.
\end{abstract}

Derrida Today 6.2 (2013): 197-221

DOI: $10.3366 /$ drt.2013.0064

(C) Edinburgh University Press

www.euppublishing.com/drt 
A pervasive theme throughout much of Jacques Derrida's work is an engagement with dynamic spatial dimensions to understanding. They are spatial movements that are always somewhat hors de vue. Derrida is at the threshold of an entirely other text. This text involves a spatial opening prior to language, and yet, seeped into language. A preoccupation with space encompasses not only his earlier work such as Writing and Difference but also later interrogations in Archive Fever. A common thread in these works is an engagement with interpreting Freud's conceptions of the unconscious in spatial terms. He seeks 'a new psychoanalytic graphology', suggesting tentatively that Melanie Klein's work 'perhaps opens the way' (Derrida 1981, 231).

Building on Derrida, this paper seeks to develop key aspects of such a new dynamic psychoanalytic graphology through specific candidate structures of interactive spatial relation. This psychoanalytic graphology is argued to be a pervasive, and yet implicit, feature of Freud's own direct accounts of repression. It occurs at a level of systemic interactions identified by Derrida, a level prior to Freud's typically causal preoccupations. This paper excavates a common domain of preoccupation for both Derrida and Freud in relation to repression, including spatial dimensions underlying inversions, connection and separation. I will argue that a key mediating insight to bridge Freud and Derrida's concerns emerges from a radical reconstruction of a somewhat neglected aspect of structural anthropologist Claude LéviStrauss' $(1966$; 1963; 1977) work on spatial relations prior to myth, namely, interactions between diametric and concentric structures of relation (see below Figure 1 and Figure 2). A diametric spatial opposition is one where a circle is split in half by a line which is its diameter, or where a square or rectangle is similarly divided into two equal halves. In concentric spatial relation, one circle is inscribed within another larger circle; in pure form, the circles share a common central point.

Derrida recognizes that at least some dimensions to Lévi-Strauss' work on myth harmonize with his own preoccupations. In opening a space for a supposedly entirely other text, Derrida invites scrutiny of a level prior to myth. Commenting on Lévi-Strauss' discourse on myths, Derrida observes: 'What appears most fascinating in this critical search for a new status of discourse is the stated abandonment of all reference to a center, to a subject, to a privileged reference, to an origin, or to an absolute archia' (Derrida 1981, 286). Derrida extols the virtues of this 


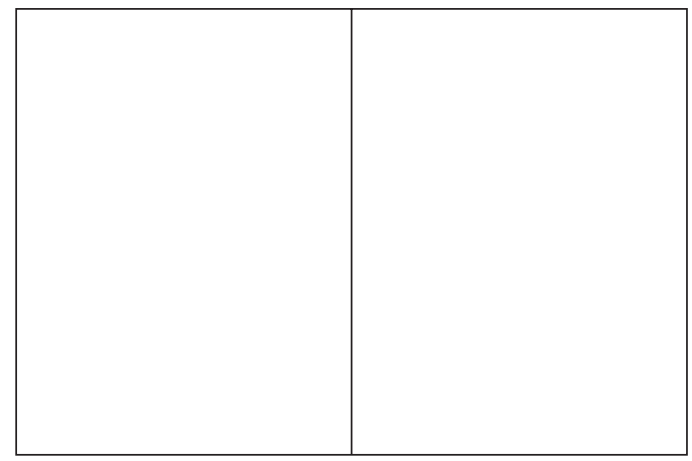

Figure 1. Diametric dualism.

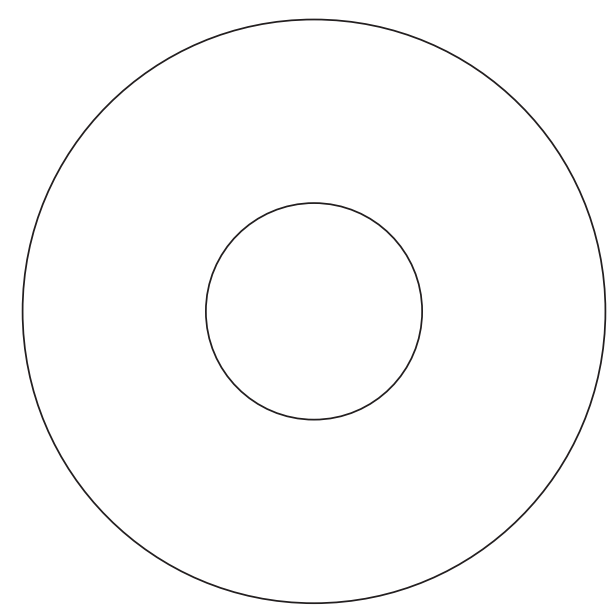

Figure 2. Concentric dualism.

development in Lévi-Strauss' The Raw and the Cooked: 'From the very start, Lévi-Strauss recognizes that the Bororo myth which he employs in the book as the 'reference myth' does not merit this name and this treatment' (Ibid. 286). Derrida continues:

There is no unity or absolute source of the myth. The focus of the source of the myth are always shadows and virtualities which are elusive, unactualizable and nonexistent in the first place. Everything begins with structure, configuration or relationship. The discourse on the acentric structure that myth itself is, cannot itself have an absolute subject or an absolute center. (Ibid. 286) 
There is no myth as a still point of the turning world. There is no Archimedean point for myth. A fundamental reference point has been expelled from a mythical Eden of the mythic. If myths transform one into another and it is the relation or structure of myths that is more fundamental, this requires further interrogation of this background relation. This invites a renewed focus on spatial and temporal dimensions.

Within a guiding structuralist framework in anthropology, LéviStrauss explicitly locates diametric spatial structures not only within myths but prior to them as an implicit organizing discourse. LéviStrauss uncovers diametric opposition as being a reversal, while describing 'symmetrical inversions' (Lévi-Strauss 1977, 247) in a space of differential relation for Mandan and Hidatsa myths:

these myths are diametrically opposed... In the Mandan version... two earth women who are not sisters go to heaven to become sisters-in-law by marrying celestial brothers. One who belongs to the Mandan tribe, separates from an ogre, Sun, with the help of a string which enables her to come back down to her village. In revenge, Sun places his legitimate son at the head of the enemies of the Mandan, upon whom he declares war. In the Hidatsa version... everything is exactly reversed. Two celestial brothers come down to earth to be conceived by human beings and born as children. Sun's sister, an ogress, is joined with an earthborn character by means of a string. She makes him her adopted son and puts him at the head of the enemies of the Hidatsa. (Ibid. 250)

Lévi-Strauss reiterates a view of diametric spatial structural opposition as expressing qualities of inverted symmetry, when contrasting the myth of the Thompson and the Coeur d'Alene with that of the Chilcotin (Ibid. 262). Echoing a view of symmetry as 'transformations which sometimes result in the meaning being turned inside out' (Ibid. 260), he invokes descriptions of myths, framed by a spatial understanding of their relation as involving, what amounts to a mirror image:

One often observes... that mythological systems after passing through a minimal expression, recover their original fullness on the other side of the threshold. But their reflection is inverted a bit like a bundle of light rays entering into a camera obscura through a pin-point opening and forced by this obstacle to cross over each other. The same image seen rightside-up outside is reflected upside-down in the camera. (Ibid. 259, 260)

Strictly speaking, a mirror image is plane symmetry, rather than the line symmetry of diametric dualism. Nevertheless, diametric plane, line 
and point symmetry all accommodate a view of symmetry as reversal or inversion. It is both a two-dimensional and three-dimensional text.

Observed by Lévi-Strauss as structures underlying myths and as social structures in space, Lévi-Strauss did not make the radical conceptual leap to examining this ancient structure of diametric relation as giving expression to emotional dimensions and repression in the unconscious. This is despite Freud's account, in his Introductory Lectures of 1916-17, of resistance and repression in similar terms of a kind of inverted symmetry, echoing also his Five Lectures on Psycho-Analysis (1910a, 25-27):

Every mental process... [except external perception] exists to begin with in an unconscious stage or phase... it is only from there that the process passes over into the conscious phase, just as a photographic picture begins as a negative and only becomes a picture after being turned into a positive. Not every negative, however, necessarily becomes a positive; nor is it necessary that every unconscious mental process should turn into a conscious one. (Freud 1916-17, 295)

Freud's underlying vision here is that meaning is, as in Lévi-Strauss' words, 'turned inside out'.

Derrida's concern with time, memory and the unconscious archive examines a spatial dimension, as the archive is 'already a psychic spacing' (Derrida 1996a, 91-92): 'The archive takes place at the place of originary and structural breakdown of the said ["spontaneous, alive"] memory' (Ibid. 11). For Derrida, understanding of the archive is key to the conceptualization of repression to unlock a domain prior to 'logocentric repression' (Derrida 1981, 197) and purportedly antecedent to individual repression. Referring to Freud's Project for a Scientific Psychology (1895), Derrida prioritises focus on spatial concerns:

we repeatedly find a persistent attempt to account for the psyche in terms of spacing, a topography of traces, a map of breaches; and we repeatedly find an attempt to locate consciousness or quality in a space whose structure and possibility must be rethought. (Derrida 1981, 205)

Commencing with diametric spatial relations, such as mirror image inverted symmetry, a key issue is how this proposed psychoanalytic graphology implicitly pervades Freudian accounts of repression and the 
unconscious. Further to this, it is necessary to comprehend why such Freudian accounts are insufficient as merely logocentric repression, and what Derrida is adding beyond this.

For Freud, the diphasic pattern of reactive prohibition and substitutive satisfaction, as well as the mirror image inversion between passive and active roles, are features of obsessional neurosis. In Wolf Man, Freud strongly emphasises the interplay of two diametrically opposing states, 'sadistic aggressiveness towards the father and a tender passive attitude to him' which 'form a pair of opposites' (Freud 1925-26, 106). The passive orientation is a mirror image of the active one involved in aggression, likewise the tender attitude towards the father and the sadistic attitude towards him. Each is both an instantiation of a repressive principle and a denial of the other repressive principle. Significantly, Freud goes so far as to recognize that repression is itself divided, for example, in such cases of obsessional neurosis, into two conflicting processes (Ibid. 106). Freud extends this dualistic structure, in effect, making it a general feature of obsessional neurosis:

The symptoms belonging to this [obsessional] neurosis fall, in general, into two groups, each having an opposite trend. They are either prohibitions, precautions and expiations - that is, negative in character-or they are, on the contrary, substitutive satisfactions which often appear in symbolic disguise. (Ibid. 112)

The reaction to prior trauma tends to impose a diametric opposition of a repressive split between trauma and reactive prohibition, precaution and/or expiation. In his comments on Freud's Rat Man case, Sherwood implies that this inverted symmetry insight of Freud challenges conventional Western logic: 'And why should the patient have felt such remorse at the father's death if he hated him? It is items like these which present at least a prima facie incongruity' (Sherwood 1969, 222). Freud in effect conceptualises beyond Western A/Non-A logic with mirror image structures.

Diametric projection underlies the spatial structure of play highlighted in Freud's (1920) account of his grandson Ernst's game of fort$d a$ inviting an interplay of disappearance-return of a wooden reel. According to Freud, the child compensated himself for the instinctual renunciation he had made in allowing his mother to go away, without protesting, by staging the disappearance and return of the objects within his reach. Turning his experience into a game: 'At the outset he was in a passive situation - he was overpowered by the experience; but by repeating it, unpleasurable though it was, as a game, he took on an active 
part' (Freud 1920,16). Freud conceptualised the function of repetitive play as the child becoming an active 'master of the situation', through repeating that which had left a significant emotional impression. Freud assessed the goal or function of repetitive play as follows:

It is clear that in their play children repeat everything that has made a great impression on them in real life, and that in doing so they abreact the strength of the impression and... make themselves master of the situation... As the child passes over from the passivity of the experience to the activity of the game, he hands on the disagreeable experience to one of his playmates and in this way revenges himself on a substitute. (Ibid. 16-17)

The game of disappearance-return is an example of reversal expressing diametric structured behaviour and experience. This mirror image reversal is not a cancelling of one pole by the other. Both coexist in an uneasy tension. Elsewhere, Freud recognised that mirror image inversions in dreams are not necessarily related to pathology, being prevalent in birth-dreams, and 'contrariwise', 'just the reverse' dreams (Freud 1900, 526; 439); once again, this implies a spatial logic or discourse.

In the Schreber case of psychosis, Freud describes a series of reversals or diametric structured inverted symmetries, the 'combination of reverential subordination and rebellious resistance... found in Schreber's relationship to his God' (Freud 2002, 40). This chain or system of reversals includes Schreber's mission from God as redeemer of the world, God becoming a persecutor and Schreber mocking God. Encrustation of experience within a diametric space process took the forms of a series of reversals and mirror image splits into heightened diametric experience (see also Freud 2002, 39, on Schreber's splits into 'upper' and 'lower' God, and 'upper' and 'middle' Flechsig). That these diametric spatial features of inversion go far beyond the Schreber case for paranoia and psychosis is evident from Freud's following position:

The pathological process in paranoia... makes use of the mechanism of projection... The typical case of such a conflict is one between the two members of a pair of opposites - the case of an ambivalent attitude, which we have examined in detail as it appears in someone mourning the death of a loved relative. (Freud 1912-13, 92)

Two of the reversals expressing inverted symmetry of diametric structural projections in Schreber are also arguably largely consistent with obsessional neurosis. These include Freud's words regarding Schreber: 
Before he was inclined towards sexual asceticism and was a doubter with respect to God, while after the illness had taken its course, he became a believer in God and devoted to voluptuousness. (Freud 2002, 21)

and

the tone of the emotion turned into its opposite; the individual now hated and feared as a result of his persecution was once loved and admired. The persecution established by the delusion serves above all to justify the patient's emotional transformation... his attitude towards him has in the meantime diametrically changed. (Ibid. 32, italics mine)

These reversals operate largely within the diametric structure itself rather than beyond this structure. Both reversals are defensive modes of a withdrawal into an increasingly more restrictive spatial structure underlying and governing experience. Diametric structures of mirror image reversals provide a corralling of flows of energy. In Freud's neglected graphology, an implicit danger is that repressive diametric spatial structural projections colonize experience and the unconscious.

What emerges here from Freud's accounts is not only two levels of diametric spatial structured experience (in obsessional neurosis and psychosis) in repression and the unconscious; a clear implication from Freud's accounts is that a consistent chain or system of diametric structured spatial relations pervades the unconscious. It is evident that diametric spatial features are inextricably entwined with repressed, reactive to trauma, features of the unconscious as a system. In other words, the variable life histories' causal effects produce a system level response in the unconscious of a diametric structured spatial background for experience in both obsessional neurosis and psychosis, though with perhaps different functions for each diametric process. Development in experience is a movement in excess of diametric spatial structures that are bound within the restricted domain of a mirror image relation. The question arises as to whether diametric spatial relations are a circumscribed part of another wider spatial mode of relation; a relation that is more than simply a horizonless opening and not simply a defiance of the limitations of the restricted space of diametric relations.

$*$

Derrida's discourse on the 'archive' in the unconscious offers a challenge to a truth located in linear historical time as being fundamental; it is a rejection, as so much else of his work, of simple narratives of origin. 
A Derridean critique would focus on the limitations of this diametric spatial mirror image symmetry as logocentric repression founding the construction of subjectivity. Though allowing for some division within repression, and acknowledging that mirror image inversion amounts to a challenge to Western logocentric principles of non-contradiction, a Derridean perspective would consider diametric spatial relation as being too static and requiring a prior background dynamism and structure of difference for the unconscious. Freud does recognise that these diametric structured reversals are problematic and in need of working through for change. They are the hidden spaces of repression upon which subjectivity is constructed: a restricted space, a confined site for integration through mirror image symmetries.

The mirror image construction of subjectivity, as part of a Freudian logocentric repression, does not go far enough for Derrida. While diametric spatial inversions offer a step forward in providing a spatial discourse or graphematics, Derrida would accentuate the limitations of such diametric mirror image truths as being chained within a Western metaphysics of knowledge as sight going back to Plato. Nick Mansfield (2000) locates Derrida as part of what he provisionally describes as an anti-subjective tradition that highlights the illusionary certainty of this historical construct. On this reading of diametric mirror image relations, the inverted image is a constructed truth which may be illusory. The lapse into mirror image split relations is an occlusion of a prior truth. Movement is needed from diametric mirror image inversion in excess of this restricted diametric spatial realm. This interruption of diametric mirror image space by another invites an opening towards other spaces such as concentric relations. These provide not stable fixities but rather tendencies and directions for experience within a larger fluctuating system of processes. Moreover, it is to be recognised that power is not somehow separate from or subsequent to the construction of the subject as a diametric spatial site of experience. The locus of power is built into the diametric spatial polarity itself, in the tension between both poles in mirror image inversion of the other.

Yet any possible movement away from diametric spatial relation towards other spatial modes, such as concentric relation, requires clarification of the features through which these spatial modes can mutually interact and even replace each other. Beyond mirror image symmetry, a framework is required to be developed that allows for interaction and movement between diametric space and other spaces, such as concentric spatial relation, in order to move beyond a Freudian logocentric repression. Concentric spatial relation does also offer an 
example of symmetry but not of inverted symmetry; the symmetrical reflection in concentric polarity is the same pole not the other different pole as in diametric polarity. The contrast is between diametric symmetry as inversion and concentric symmetry as unity. Thus, though different in their kinds of symmetry, diametric and concentric spatial relations share a common domain of discourse with regard to symmetry.

For Derrida, the space itself of the archive is in some way divided and 'there is no archive without a place of consignation, without a technique of repetition and without a certain exterior' (Derrida 1996a, $1)$. This division within memory, traces of memory and traces of the archive, 'that objectivizable storage called the archive' (Ibid. 26), invites a concomitant focus on an absence in claims of presence. This invites further interrogation of issues of division, separation, interaction and connection, as well as repetition, both in Freudian conceptions of the unconscious and in going beyond logocentric repression to another domain of relevance.

It is this dimension of separation and connection which invites a discourse pertinent to diametric and concentric spatial relation. Beyond mirror image inverted symmetry, Lévi-Strauss overlooked another key relational entailment of diametric dualism, namely, that both oppositional realms are basically detached and can be further smoothly detached from the other. A spatial relation of diametric dualism assumes separation and any connection between the parts is on the basis of this assumed separation (Downes 2003; 2010; 2011). A key relative difference between diametric and concentric relations, overlooked by Lévi-Strauss' empiricism, is ascertainable in principle. It is evident that the inner and outer poles of concentric dualism are inextricably attached to each other, unlike in diametric dualism; both concentric poles coexist in the same space, and thus, the outer circle overlaps the space of the inner one. The outer circle surrounds and contains the inner circle. The opposite that is within the outer circle or shape cannot detach itself from being within this outer shape. Notwithstanding that the outer circle or shape can move in the direction of greater detachment from the inner circle, it cannot, in principle, fully detach itself from the inner circle in concentric relation (even if the inner circle becomes an increasingly smaller proportion of the outer). Full detachment could conceivably occur only through destroying or altering the form of the other pole. Full detachment could occur only through destroying the very concentric nature of the whole relation itself. Concentric spatial relation invokes an alterity that is not reducible to simple opposition. In contradistinction, in 
diametric dualism both oppositional realms are basically detached and can be further smoothly detached from the other.

These conclusions operate for both dualisms, whether they are viewed as being two-dimensional, or three-dimensional. A concentric dualism assumes connection between its parts and any separation is on the basis of assumed connection, whereas diametric dualism assumes separation and any connection between the parts is on the basis of this assumed separation (Downes 2003, 2010). As structures in relational difference, this contrast is a relativistic one of degree.

The contours of a Derridean text prior to Freud's logocentric repression give expression not only to the interconnectedness of space and time as an interplay, but also bring an intensification of concentration on dimensions of rupture and connection:

Temporality as spacing will be not only the horizontal discontinuity of a chain of signs, but also will be writing as the interruption and restoration of contact between the various depths of psychical levels: the remarkably heterogenous temporal fabric of psychical work itself. (Derrida 1981, 225)

This focus on interruption is an expansion of the two-way repressive movements highlighted by Freud (1925-26) in mirror image symmetry for obsessional neurosis. Derrida seeks a wider view of systemic repression and connection, as a series of interruptions and restorations at different heterogeneous levels. This wider view gains some succour also from Freud's acknowledgement that 'instead of a single repression we have found a collection of them' (Freud 1925-26, 107). A Derridean background questioning involves examination of the differences and connections between these systemic collections of repressions. It highlights the need for concentrating on how to relate and not relate these repressions to each other as structures of difference.

Interruption and restoration implicates both diametric spatial process dimensions of assumed separation and concentric spatial projections of assumed connection. A view of spacing as dynamic leads to the proposed psychoanalytic graphology of diametric and concentric spatial differential relation through this focus on interruption and restoration-assumed separation and assumed connection-as pervading the different heterogeneous aspects of the unconscious. Interaction between diametric and concentric spaces of assumed separation and connection respectively requires this wider systemic focus of Derrida, amplifying Freud, on relations between collections of repressions. The divisions in these collections of repressions encompass what Derrida (1996a) refers to as 'archive fever', as contradictions in a divided 
archive of the unconscious, what he describes as 'the ungraspable and invisible difference between breaches' (Derrida 1981, 201) in the trace as memory.

Repression and the unconscious is for Derrida a dynamic process of archivization. Suggesting that 'the archivization produces as much as it records the event' (Derrida 1996a, 17), Derrida argues that Freud

wants to exhume a more archaic impression, he wants to exhibit a more archaic imprint than the one the other archaeologists of all kinds bustle around, those of literature and those of classical objective science... an impression that is almost no longer an archive but almost confuses itself with the pressure of the footstep that leaves its still-living mark on a substrate, a surface, a place of origin. (Ibid. 97)

The process dimensions of concentric assumed connection and diametric assumed separation provide a level of systemic interactions between the various depths of psychic levels. These systemic interactions emerge whether in moving beyond the mirror image symmetries in neurosis and more radical splits of assumed separation in psychosis, or in relating constellations emerging from reactions to external events to a prior spatial organizing principle to repression in unconscious relations. They offer a spatial interplay for engaging with difference between breaches in systems of repression and memory.

Though Klein (1997a; 1997b) gives this more extreme emphasis, repression as a process of splitting or assumed separation is a central feature of Freud's understanding; even beyond assumptions of a repressive split underlying the divided poles of mirror image inversions. Freud's account of the history of the psychoanalytic movement states, in relation to his framework at the end of the Breuer period, that 'I looked upon psychical splitting itself as an effect of a process of repelling which at that time I called "defence", and later, "repression"'(Freud 1914-16, 11). Much later, Freud also explores a 'splitting of the ego in the process of defence' discussing 'a rift in the ego which never heals but which increases as time goes on' (Freud 1937-39, 276). That splitting or assumed separation is, for Freud, not simply an outcome but also a process associated with repression can be seen in his The Ego and the Id where he argues: 'The repressed is only cut off sharply from the ego by the resistances of repression' (Freud 1923, 24). From this, it is evident that the assumed separation of diametric spatial structures gives expression to a key feature of repression as a splitting process and that diametric space offers both a structure and a dynamic process of inducing assumed separation in its movement and projection. The 
proposed interplay between diametric and concentric spatial relations invites movement towards healing these splits, towards a concentric assumed connection to interrupt, overcome and reconstruct the assumed separation of repressive diametric relations.

Freud (1920) hypothesised that the function of repetition compulsion antedated the pleasure principle. Building on the edifice of Freud, Derrida describes '[a] compulsive, repetitive and nostalgic desire for the archive, an irrepressible desire to return to the origin, a homesickness, a nostalgia for the return to the most archaic place of absolute commencement' (Derrida 1996a, 91). Whether this is equivalent with Freud's compulsion to repeat or otherwise, conceptualizing both diametric and concentric spatial structures dynamically, as projections, requires recognition that a repetition and return takes place through such projections. The dynamic process of constructing such projections upon experience and the environment, and within the system of the unconscious, is itself a process of repetition: of repeating the structure being projected by means of the projection. Thus, envisaged as a structural projection, the diametric spatial relation is both a structure and a dynamic process imposing itself upon its environment. Likewise concentric spatial structures and concentric spatial processes project themselves dynamically upon their environment. Projection is itself an attempt to return to a prior state of affairs, namely, to the projected structure itself. It is a pre-causal process. Through projection this diametric spatial structure both repeats itself and engages in a diametric process of turning relations into diametric structures. The diametric process is an attempted return to the origin of the diametric structure; it is a spatial movement towards a static, diametric structural relation. This movement is under the dominion of diametric structured spatial projections dictating to the unconscious. And similarly, an event and ongoing process of return occurs with the different direction of concentric spatial projections.

It is apparent that a key feature of concentric and diametric spatial discourses is that they are mutually interactive movements. They are structures of relation but also structures in relation, and are not simply separate individual structures but are interlinked so that increase in one is compensated for by decrease in the other. Concentric spatial structures give way to diametric ones and vice-versa in a relativistic relational process. As each is a displacement and deferral of the other, the mutual tension in which they are held brings a resistance to either existing in full presence. Lévi-Strauss observed that both dualisms tended to coexist in 'functional relation' (Lévi-Strauss 1977, 73). This echoes the 
structuralist insight that meaning for other systems, such as language, occurs through relational difference, rather than in a single term. Yet Lévi-Strauss only explicated in rudimentary form any meaning given expression through these structures of differential relation. A spatial discourse of implication needs further development to extract spatial entailments. This amplification resonates with Derrida's account that 'psychic life is neither the transparency of meaning nor the opacity of force but the difference within the exertion of forces' (Derrida 1981, 201).

The relational differences between concentric and diametric dualism are not qualities that are in some way essential or intrinsic to either structure, considered as individual isolated structures; they are not to be abstracted from the context of their mutual relation. In Derridean terms, the key dynamic is not in the individual structures but in their structural traces of differential relation, as aspects of a potentially open chain of differential structures, as part of a dynamic process of directional movement. It is not an attempt to find static categories which cohere. Whereas Derrida interprets Freud as wanting 'to think force and place simultaneously' and views 'differences in the work of breaching' as concerning 'not only forces but also locations' (Ibid. 204), a basically similar concern with a simultaneous interplay between directional and positional dimensions to diametric and concentric spaces exists for current purposes. Derrida focuses on the relation of sameness and difference in relationship:

What is the division of being between the same and the other? Is it a division between the same and the other, which does not suppose, at very least, that the same is the other's other, and the other the same as oneself ? (Ibid. 127)

Concentric and diametric structures of relation offer models of sameness and otherness - of assumed connection and separation - which accommodate conceptions of sameness and difference. They offer dynamic structures of differential relation. However, it must be noted that Derrida endeavours to avoid placing a reified image before the idea; this serves as an important warning against reduction of concentric and diametric relation to merely abstract decontextualised schemata. Derrida eschews abstract essences, whether essences are postulated as categories (Sayer 1997) or otherwise, his is a quest for a space that is non-cognitive or at least a precognitive threshold; a space always already deferred. A movement more radical than reliance on the visual, aural or haptic is needed, being neither in thrall to metaphysics, nor mourning the certainty of binary opposition. This invites examination of a spatial 
dimension that is in some way prior to everyday sight and beyond a metaphysical tradition reliant on the sensory-nonsensory distinction going back to antiquity with Plato. Significantly, dimensions of diametric spatial relation as assumed separation and concentric spatial relation as assumed connection open up a site of interaction that is not contingent of visual metaphors of light.

As an interactive spatial mode with diametric space, concentric relation provides a spatial opening that includes affect and also provides a dynamic spatial movement in this interactive mode of relation. As a projection of possibility, it is a dynamic process as much as a static structure. However, an opening from diametric and towards concentric spatial structures of experience and relation is by no means a deterministic or simple teleological process. A shift from diametric spatial structures also invites the danger of a further fragmentation and splitting in this restructuring, so that the turning open toward concentric spatial relation may not necessarily come forth. It is not simply that a loss of meaning may occur in the horizon shift away from diametric spatial relation; concentric directions of opening need not be confined to injunctions towards meaning making. Whereas concentric spatial movements unsettle the fixities of diametric spatial relations, this is not reducible to a purpose of finding a different static mould or cognitive mapping for truth, reality or experience. The directions of the contours of this different experiential angle of relation than the diametric do not map in linear fashion onto a correspondent cognitive construction of reality. As Heidegger would describe it, a questioning of being is not reducible to a mere hypostatized worldview. It is not, for Derrida, a return to a simple naive origin or home. Derrida's search for a psychoanalytic graphology is a quest for a spatial membrane that is not mere matter invested with logocentric values of thingness; neither is it a conception of reality opposed to the idea.

$*$

Lévi-Strauss' reliance on an analogy between the structure of myths and that of structural linguistics has been strongly questioned (e.g., Caton 1987). While his epistemology for diametric dualism is drawn from linguistics, this does not require that the cross-cultural observations of diametric dualism be confined to examination from a paradigm drawn from linguistics. Arguably, it was the very cage of this paradigm that 
prevented Lévi-Strauss from expanding upon the proposed affective dimensions for this structure of relation. It is important to emphasise that Lévi-Strauss' account of diverse empirical observations of diametric spatial dualisms as mirror image inverted symmetry is but one part of his structural anthropological project. The examination of diametric and concentric projection for this proposed new psychoanalytic graphology is to develop a position beyond Lévi-Strauss, rather than simply echoing his fundamental assumptions.

There is also a need to go beyond a conception of Derrida as being either for or against the work of Lévi-Strauss. Most of Lévi-Strauss' structuralism can be safely discarded for the contours of Derridean concerns; a process of critique of Lévi-Strauss is necessary to pave the way for the neglected apogée of his thought concerning spatial relations.

The scope of Derrida's critique of Lévi-Strauss' structuralism is wide and varied. These objections include from universalist and teleological claims, to reification of structures (so that structure becomes confused with meaning), to a nostalgia for origins and innocence, to a structuralism bound by the subject-object relation, to a transcendence as totality - echoing Jean-Francois Lyotard's critique of metanarratives - to the certainty of grounded structures where the entire history of the concept of structure' must be thought of as 'a series of substitutions of center for center' (Derrida 1981, 279). Derrida's search is for an 'opening which will frustrate the structuralist project' (Ibid. 160). Derrida's questioning of the 'structurality of structure' (Ibid. 278) in Lévi-Strauss' structuralism, is a background self-referential questioning resonant with early Heidegger's questioning of the temporalizing of temporality, and scrutiny of the status of the background relation between the ideal and the real, as itself being real or ideal (to move beyond a chimeric hegemony of one pole over the other). Derrida's entirely other text necessitates a space beyond such binary opposition.

Derrida's critique of reification regarding structure raises further distinctions between the thought of the structure itself, speech or language describing the structure, and experience of the structure. $\mathrm{He}$ indicts the reification of structures as 'confusing meaning with its geometric, morphological, or in the best of cases, cinematic model' (Ibid. 16), where 'structure becomes the object itself, the literary thing itself. It is no longer... a heuristic instrument' (Ibid. 15). Yet these criticisms apply not only to structures but to all images.

It is worth emphasizing, however, that Lévi-Strauss argues for an interplay between structure and content in contrast to formalism ${ }^{1}$. In the words of Lévi-Strauss: 
Contrary to formalism, structuralism refuses to set the concrete against the abstract... Form is defined by opposition to material other than itself. But structure has no distinct content; it is content itself, apprehended in a logical organisation conceived as property of the real. (Lévi-Strauss 1977, 115)

This not only advances Lévi-Strauss' position beyond a reified view of structures. Images as reifications locked within assumptions of a subjectobject dualism invite the question as to the possibility of space which is not simply at the level of reified images. This requires acknowledgment, however, of Derrida's cautionary note that thought concerning space cannot be equated in cursory fashion with language on space or experience of space.

Derrida rightly challenges some statements of Lévi-Strauss which have no direct relation to spatial concerns, such as the latter's view that 'the sum of... knowledge' in the Western world prior to 'the invention of writing and the birth of modern science' has gone 'up and down' rather than having 'a steady increase' (Derrida 1997, 129). He problematises the very conception of a quantity of knowledge and exposes Lévi-Strauss' assertion as being neither true nor false but simply meaningless; it is bereft of construct validity. Derrida (1997) goes on to reject Lévi-Strauss' nostalgia for lost origins and assumptions of an original innocence and natural goodness in primitive tribes such as the Nambikwara. This deconstruction challenges the view of violence being derivative from a prior innocence. Here Derrida is, in effect, avoiding a diametric oppositional split between a phase of innocence and subsequent violence. Another aspect of reification criticised by Derrida is the tendency to place the idea before the experience, putting 'the notion of an Idea or "interior design" as simply anterior to a work which would supposedly be the expression of it'; this is 'a prejudice: a prejudice of the traditional criticism called idealist' (Derrida 1981, 11). Yet a spatial background interplay is being sought by Derrida, so that it is not simply a question of rejecting all forms of dynamic structural relation. Furthermore, Derrida has an objection to structuralism's 'preestablished' teleological framework (Ibid. 25).

The epistemological commitments underlying Lévi-Strauss' crosscultural observations of concentric and diametric dualism require modification, in order to relate them to Derrida's entirely other text. Lévi-Strauss' reliance on an analogy between the structure of myths and that of structural linguistics has been strongly questioned (Caton 1987). While his epistemology for the dualisms is drawn from linguistics, this does not require that the concentric and diametric spatial structures 
of relation, and their relative differences, be confined to examination only from within an epistemological paradigm drawn from linguistics. Arguably, it was the very cage of this paradigm that prevented LéviStrauss from expanding upon the proposed spatial-psychoanalytical uncovering of these structures of differential relation.

These ancient structures of-relation-in-relation share with language the feature of being a trans-subjective system of relations. However, as a discourse of implication this does not make the spatial dualisms reducible to a linguistic system. Paths are to be developed which lead far beyond Lévi-Strauss' structuralism in giving rise to the implicit spatial discourse of diametric and concentric differential relation. In making such steps, the relational differences between concentric and diametric spatial movements are, most importantly, not being subsumed within the Procrustean bed of Lévi-Strauss' search for Cartesian mental structures, noted by Eugene D'Aquili (1975). While Lévi-Strauss' account of diverse empirical observations of concentric and diametric spatial dualisms is but one small part of his structural anthropological project, the argument being developed for current purposes is not one which requires commitment to accepting other aspects of Lévi-Strauss' work. $^{2}$

The proposed pre-linguistic spatial discourse of implication is not reducible to silent gestures, that is, socially constructed non-verbal communication. Without necessarily having to endorse a Beckettian minimalism with regard to language, it is possible to at least partially identify this silent, pre-linguistic spatial opening of the trace of diametric and concentric spatial relations, with Samuel Beckett's quest for the numinous:

As we cannot eliminate language all at once, we should at least leave nothing undone that might contribute to its falling into disrepute. To bore one hole after another in it, until what lurks behind it-be it something or nothing-begins to seep through. (Beckett 1983, 172)

Fluid spaces of concentric relation are part of an interplay with diametric structures, as holes lurking behind language. In Derrida's evocative words, this movement, 'give[s] voice to the dynamis of a silence' (Derrida 1981, 165). This space invites a silence, a movement that invokes - but is not reducible to-aural dimensions, and is not reducible merely to a Western visual metaphysics.

It is evident that diametric and concentric spatial relations are not only a system of relations interacting within itself. Their traces are also projected into other systems of relation such as language and 
behaviour. They offer a domain of interactions that is prior to causal level explanations, prior to intentionality, and prior to language systems, yet interacting with them.

A notable feature of this proposed psychoanalytic graphology is that the interplay between diametric and concentric spaces offers a movement beyond the subject-object dualism in this reconstruction of subjectivity pertaining to unconscious structures of experience. Exploring boundaries between subjectivity and objectivity in repression and the unconscious, Derrida tentatively enters into a space before the subject-object relation, 'the pressure of the printing, the impression, before the division between the printed and the printer' (Derrida 1996a, 18). The printer and the printed (including the image) exist against a prior background space of relation; printer and printed are arrested effects upon a prior space.

Early Heideggerian themes, woven into the tapestry of Derrida's thought, include: problematization of a truth prior to the subjectobject relation of the printer and the printed; a dimension of temporality invoked as pivotal to understanding this truth; and Derrida's reconciliation with an affective dimension, thereby implicating an affinity with Heideggerian care and ekstatic time. This printer-printed, footstep-substrate, subject-object relation is unfolded by Derrida through a dimension of time, the 'instant': 'In the instant when the imprint is yet to be left, abandoned by the pressure of the impression. In the instant of the pure auto-affection, in the indistinction of the active and the passive, of a touching and the touched' (Derrida 1996a, 98).

Derrida searches for a language to overcome the subject-object dualism, when seeking to locate a primordial impression, while a temporal framework, as the 'instant', is invoked. While Ian Hunter (2006) argues that Derrida's structure of difference cannot be outside history, it would seem that for Derrida here, like the early Heidegger (1962), there is a temporal mode prior to linear historical time. Derrida's rejection of origins is not a rejection of some spatio-temporal realm of purity, of 'pure auto-affection'. Derrida continues:

where the singular imprint... barely distinguishes itself from the impression ... this is the condition of singularity .... It is the condition for the uniqueness of the printer-printed, of the impression and the imprint, of the pressure and its trace in the unique instant where they are not yet 
distinguished the one from the other .... The trace no longer distinguishes itself from its substrate. No longer distinguishing between themselves, this pressure and this imprint differ henceforth from all other impressions, from all other imprints, and from all other archives. (Derrida 1996a, 99)

Derrida's interrogation of Freudian repression and memory seeks to go beyond the printer and the printed. The printer dimension serves as a condensed account of the causal history, the event impacting upon memory and repression of memory in the unconscious. This shift in focus away from the printer (causal event) resonates with criticisms of psychoanalysis as being the production of a subject, in conjunction with the specific set of familial and social relations dominant in the culture of Freud's time (Olsen \& Køppe 1988; Mansfield 2000). Derrida is interrogating a level prior to the external, socially constructed causal history of the printed; he is going beyond a focus on events and the reaction to the event as the 'printed' memory or repression. Another significant feature of this shift of interest beyond the causal event 'printed' in relation to repression is as follows: neither Derrida's ambit of relevance nor that of the proposed psychoanalytic graphology of interaction between diametric and concentric spatial relations are confined to a Freudian preoccupation with repression and castration anxiety. Furthermore, they are not a preoccupation with other dimensions which Freud (1926) locates as central to repression (as distinct from other wider unconscious defences), such as genital fixation as causal sources of repression and the myth of the Oedipus complex in relation to repression. The graphology concerns are pre-causal and pre-mythic.

Derrida's quest is for a spatio-temporal organising principle prior to event-memory and not simply reducible to the reactive psychic constellation of the printed. The trace of the reactive constellation of the printed engages in some key relation with what Derrida calls the 'substrate'. What is the spatial structure or structuralizing process of this unique instant and substrate? What is the rationality, if any, underlying this prior temporal and spatial relation, before the division into impression and imprint, subject and object? It is important here to draw attention to a clear difference between Derrida's and Freud's understanding of the trace; the printed differs notably from Freud's (1925) account in a Note upon the 'Mystic Writing Pad'. Freud (1925, 227; 230) conceptualises the traces upon the unconscious as being 'permanent', as observed also in passing by Derrida $(1981,204)$. In stark contrast to this later emphasis of Freud (though not to that of Freud's 1896 letter to Fliess, which Derrida in Writing and Difference quotes in terms of memory-traces 
Table 1Key Dimensions of a proposed Psychoanalytic Graphology.

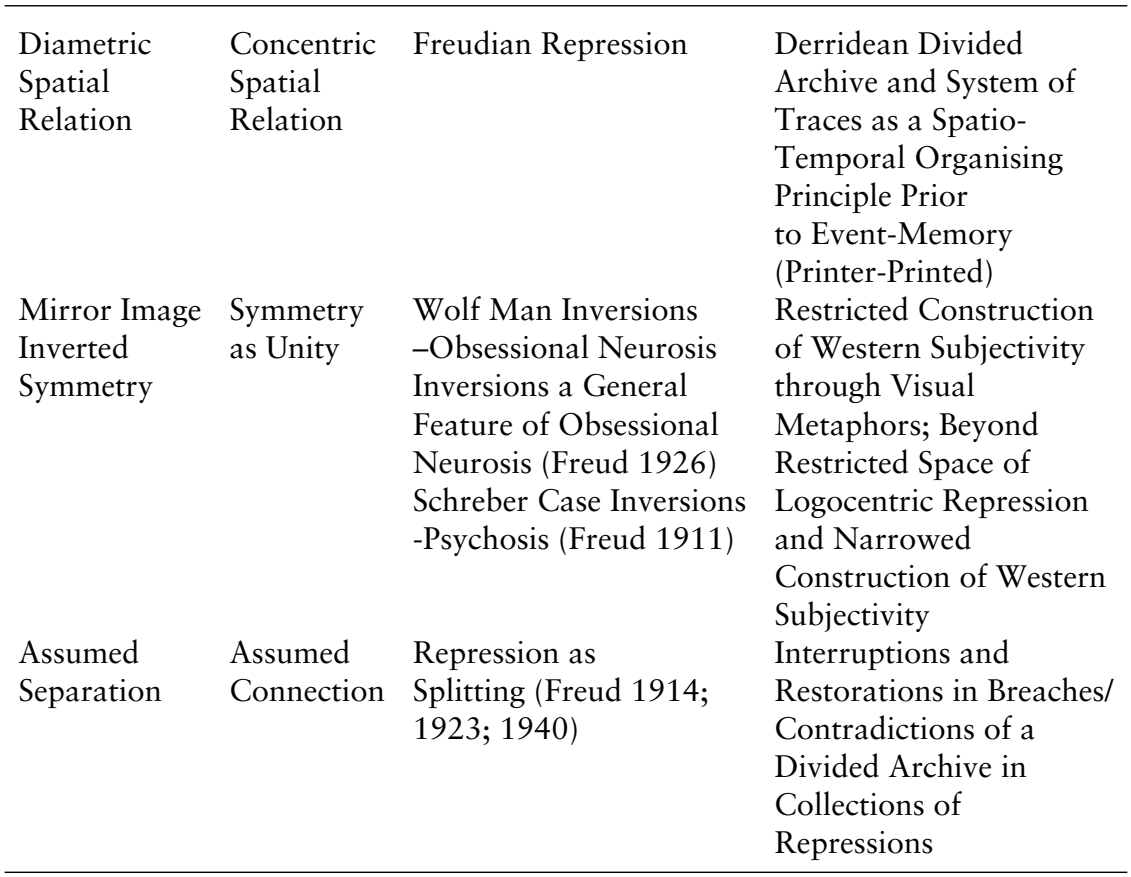

subjected to a rearrangement), Derrida opens up a dynamic background realm of interaction with the trace to challenge its permanency: 'The trace is the erasure of selfhood, of one's own presence, and is constituted by the threat or anguish of its irremediable disappearance, of the disappearance of its disappearance. An unerasable trace is not a trace, it is a full presence' (Derrida 1981, 230). Derridean erasure of the trace is conceptualized explicitly in structural terms in relation to repression:

This erasure of the trace is not only an accident that can occur here or there, nor is it even the necessary structure of a determined censorship threatening a given presence; it is the very structure which makes possible, as the movement of temporalization and pure auto-affection, something that can be called repression in general, the original synthesis of original repression and secondary repression, repression "itself". (Ibid. 230)

It is a structure which makes possible. The deconstructor par excellence allows for a dimension of purity; it contains the auto-affection dimension of the 'instant', that prior relation to the printer and printed, a mode of relation prior to the subject-object dualism. As a movement it is a 
directional structure crossing out other spatial structures. The structure of différance, the erasure of the trace in the instant between the impression and the imprint, is an erasure of a present non-origin. This invites strong resonances with the spatio-temporal structures unseating diametric mirror image symmetry.

The diametric spatial projection as a mirror image organising unconscious patterns of relation and repression for neurosis and psychosis in Freud's accounts offers a starting point for this prior spatial process of erasure. Envisaged as a dynamic spatial process, a further concentric spatial movement is needed to interact with diametric spatial relations, bringing a greater opening and interaction with background stimuli. In doing so, diametric spatial projections become unseated and potentially subject to erasure. Detailed consideration of the relation between erasure of the trace and this proposed psychoanalytic graphology of interactions between diametric and concentric spaces across respective dimensions of symmetry, separation and connection, is a task for another day.

Derrida notes that, ' $[\mathrm{m}] \mathrm{y}$ work does not... destroy the subject; it simply tries to resituate it' (Derrida 1995, 175) ? $^{3}$ This proposed psychoanalytic graphology engages with a presubjective expansion from repressive diametric spatial relations to challenge the construction of a restricted subjectivity. It is envisaged as a discourse pertaining to a more radical displacement and deferral than Freud's logocentric repression. A common spatial domain of relevance has been uncovered for diverse features of Freudian repression, including aspects of ambivalence in obsessional neurosis and psychosis, splitting of the ego, and the compulsion to repeat. This graphological domain has been developed through a range of dynamic interactive dimensions for diametric and concentric spatial movements, across common thematic concerns of Derrida and Freud, such as inversions, interruption and restoration, in their accounts of traces in systems of repression in the unconscious. In doing so, an expansion beyond a Freudian logocentric repression has been offered, resonant with Derrida's call for a wider spatio-temporal understanding of structures of differential relation, prior to causality and myth.

\section{References}

Allinson, Robert A. (2003), Space, Time and the Ethical Foundations, Burlington: Ashgate.

Beckett, Samuel (1983), Disjecta: Miscellaneous Writings and a Dramatic Fragment, ed. Ruby Cohn, London: John Calder. 
Caton, S.C. (1987), 'Contributions of Roman Jakobsen', Annual Review of Anthropology 16, pp. 223-60.

D'Aquili, Eugene (1975), 'The Influence of Jung on the Work of Claude LéviStrauss', Journal of the History of the Behavioral Sciences 11, pp. 41-48.

Derrida, Jacques (1967), La voix et le phénomène: Introduction au problème $d u$ signe dans la phénoménologie de Husserl, Paris: Presses Universitaires de France.

- (1973), Speech and Phenomena and Other Essays on Husserl's Theory of Signs, trans. D. Allison, Evanston: Northwestern University Press.

(1997), Of Grammatology, trans. G.C. Spivak. Corrected Edition. Baltimore: John Hopkins University Press.

(1982), Margins of Philosophy, trans. A. Bass. Chicago: University of Chicago Press.

(1981), Writing and Difference. trans. A. Bass, London: Routledge \& Kegan Paul.

(1995), 'Deconstruction and the Other', in ed. Richard Kearney, States of mind: Dialogues with Contemporary Thinkers in the European Mind, Manchester: Manchester University Press.

(1996a), Archive Fever: A Freudian Impression, trans. E. Prenowitz, Chicago: University of Chicago Press.

— (1996b), The Gift of Death, trans. David Wills, Chicago: University of Chicago Press.

Downes, Paul (2003), 'Cross-Cultural Structures of Concentric and Diametric Dualism in Lévi-Strauss's Structural Anthropology: Structures of Relation Underlying the Self and Ego Relation?', Journal of Analytical Psychology 48, pp. 47-81.

(2005), 'Review of "Space, Time and the Ethical Foundations" by R.A. Allinson', The Philosopher Vol. LXXXXIII, pp. 20-21.

- (2010), 'Schema Structure-Content Relativity: Part II, From Image Schemata to Background Spatial Schemata of Diametric and Concentric Relation', Cybernetics and Human Knowing 17, pp. 25-43.

- (2011), 'Concentric and Diametric Structures in Yin/Yang and the Mandala Symbol: A New Wave of Eastern Frames for Psychology', Psychology and Developing Societies 23, pp. 121-153.

Freud, Sigmund (1895), 'A Project for a Scientific Psychology', Standard Edition of the Complete Works of Sigmund Freud Vol. 1, ed. James Strachey et al., London: Hogarth Press and The Institute of Psychoanalysis (1957), pp. 283-397.

- (1900), 'Interpretation of Dreams', Standard Edition of the Complete Works of Sigmund Freud Vol. 5, ed. James Strachey et al., London: Hogarth Press and The Institute of Psychoanalysis (1953-74).

- (1910a), 'Five Lectures on Psycho-Analysis', Standard Edition of the Complete Works of Sigmund Freud Vol. 11, ed. James Strachey et al., London: Hogarth Press and The Institute of Psychoanalysis (1957), pp. 3-55.

(1912-13), 'Totem and Taboo' 1912-13, The Standard Edition of the Complete Psychological Works of Sigmund Freud Vol. 13, ed. James Strachey et al., London: Hogarth Press and The Institute of Psychoanalysis (1955), pp. 1-161.

-(1914-16), 'On the History of the Psycho-Analytic Movement' 1914-16, The Standard Edition of the Complete Psychological Works of Sigmund Freud Vol. 14, ed. James Strachey et al., London: Hogarth Press and The Institute of Psychoanalysis (1957).

(1916-17), 'Introductory Lectures on Psycho-Analysis', The Standard Edition of the Complete Psychological Works of Sigmund Freud, Vol. 16: Introductory 
Lectures on Psycho-Analysis (Part III) (pp. 241-463), ed. James Strachey et al., London: Hogarth Press and The Institute of Psychoanalysis (1963).

- (1920), 'Beyond the Pleasure Principle', The Standard Edition of the Complete Psychological Works of Sigmund Freud Vol. 18, ed. James Strachey et al., London: Hogarth Press and The Institute of Psychoanalysis (1961), pp. 7-64.

- (1923), 'The ego and the id' 1923, The Standard Edition of the Complete Psychological Works of Sigmund Freud Vol. 19, ed. James Strachey et al., London: Hogarth Press and The Institute of Psychoanalysis (1961), pp. 12-66.

-(1923-25), 'Neurosis and psychosis' 1923-25, The Standard Edition of the Complete Psychological Works of Sigmund Freud, Vol. 19, ed. James Strachey et al., London: Hogarth Press and The Institute of Psychoanalysis (1961), pp. 147-54.

-1925), 'A note on a mystic writing-pad' 1925, The Standard Edition of the Complete Psychological Works of Sigmund Freud, Vol. 19, ed. James Strachey et al., London: Hogarth Press and The Institute of Psychoanalysis (1961), pp. 227-33.

(1925-26), 'An Autobiographical Study: Inhibitions, Symptoms and Anxiety: the Question of Lay Analysis and Other Works' 1925-26, The Standard Edition of the Complete Psychological Works of Sigmund Freud, Vol. 20, ed. James Strachey et al., London: Hogarth Press and The Institute of Psychoanalysis (1978), pp. 77-172.

(1937-39), 'Splitting of the ego in the process of defence' 1937-39, The Standard Edition of the Complete Psychological Works of Sigmund Freud, Vol. 23 ed. James Strachey et al., London: Hogarth Press and The Institute of Psychoanalysis (1964), pp. 271-78.

Freud, Sigmund (2002), The Schreber Case, trans. by A. Webber. London: Penguin (first published 1911).

Heidegger, Martin (1962), Being and Time, trans. J. MacQuarrie \& E. Robinson, Oxford: Basil Blackwell (first published 1927).

Hunter, Ian (2006), 'The History of Theory', Critical Inquiry 33, pp. 78-112.

Jakobsen, Roman (1973), The Science of Language, London: William Clowes \& Sons Ltd.

Klein, Melanie (1997a), 'Notes on Some Schizoid Mechanisms' in Envy and Gratitude and Other Works (1946-1963), London: Vintage.

- (1997b), 'On the Theory of Anxiety and Guilt' in Envy and Gratitude and Other Works (1946-1963), London: Vintage.

Lévi-Strauss, Claude (1966), The Savage Mind, trans. G. Weidenfeld, Nicolson Ltd. (1963), Structural Anthropology: Vol.1. trans. C. Jacobsen \& B. Grundfest Schoepf, Allen Lane: The Penguin Press.

(1970), The Raw and the Cooked: Introduction to a Science of Mythology I, London: Jonathan Cape.

- (1977), Structural Anthropology: Vol.2., trans. M. Layton, Allen Lane: Penguin Books.

Lyotard, Jean-Francois (1984), The Postmodern Condition: A Report on Knowledge, trans. G. Bennington \& B. Massumi, Minneapolis, University of Minnesota Press.

Mansfield, Nick (2000), Subjectivity: Theories of the Self from Freud to Haraway, New York: New York University Press.

Mooney, Timothy (2003), 'How to Read Once Again: Derrida on Husserl', Philosophy Today, 47: 3, pp. 305-321.

Norris, Christopher (1982), Deconstruction: Theory and Practice, New York: Methuen. 
Olsen, Ole, and Køppe, Simo (1988), Freud's Theory of Psychoanalysis, New York: New York University Press.

Sayer, Andrew (1997), 'Essentialism, Social Constructionism and Beyond', The Sociological Review 45, pp. 454-77.

Sherwood, Michael (1969), The Logic of Explanation in Psychoanalysis, New York: Academic Press.

\section{Notes}

1. Tim Mooney (2003) relates Derrida's understanding of empiricism to a formcontent schema more primordial than perception and within which discrete impressions or sense-data receive associative overlays that unify them and render them meaningful. See Derrida 1967 and 1973. It is the interchangeability of form and content that needs further explication in relation to spatial concerns.

2. While the dynamic interaction between spatial structures of differential relation of concentric and diametric dualism requires apprehension of a framework of both space and time, Lévi-Strauss' structuralist framework is usually interpreted as excluding both space and time. Thus, for example, Roman Jakobsen's (1973, 38-9) structuralist account observes the exclusion of time and space from Saussure's conception of linguistic system which influenced Lévi-Strauss, while Lévi-Strauss' $(1966,254)$ himself explicitly rejected Jean-Paul Sartre's emphasis that all truth is historically conditioned. The issue of the temporal dimension under which movement between concentric and diametric spatial relation needs scrutiny is as an attempt to relate it to the historical without equating it with linear history. See also Allinson (2003) for an account of the need to go beyond Kantian a priori assumptions that space and time are not interconnected, and also Downes (2005) for a critical review of Allinson's account.

3. As Christopher Norris notes, Derrida accepts 'conventions of authenticity ... Their effects in day to day discourse can hardly be questioned' (Norris 1982, $111 ; 128)$. 